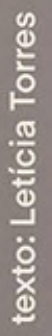

\title{
Atrizes gordas também usam figurinos
}

Fat actresses also wear costumes

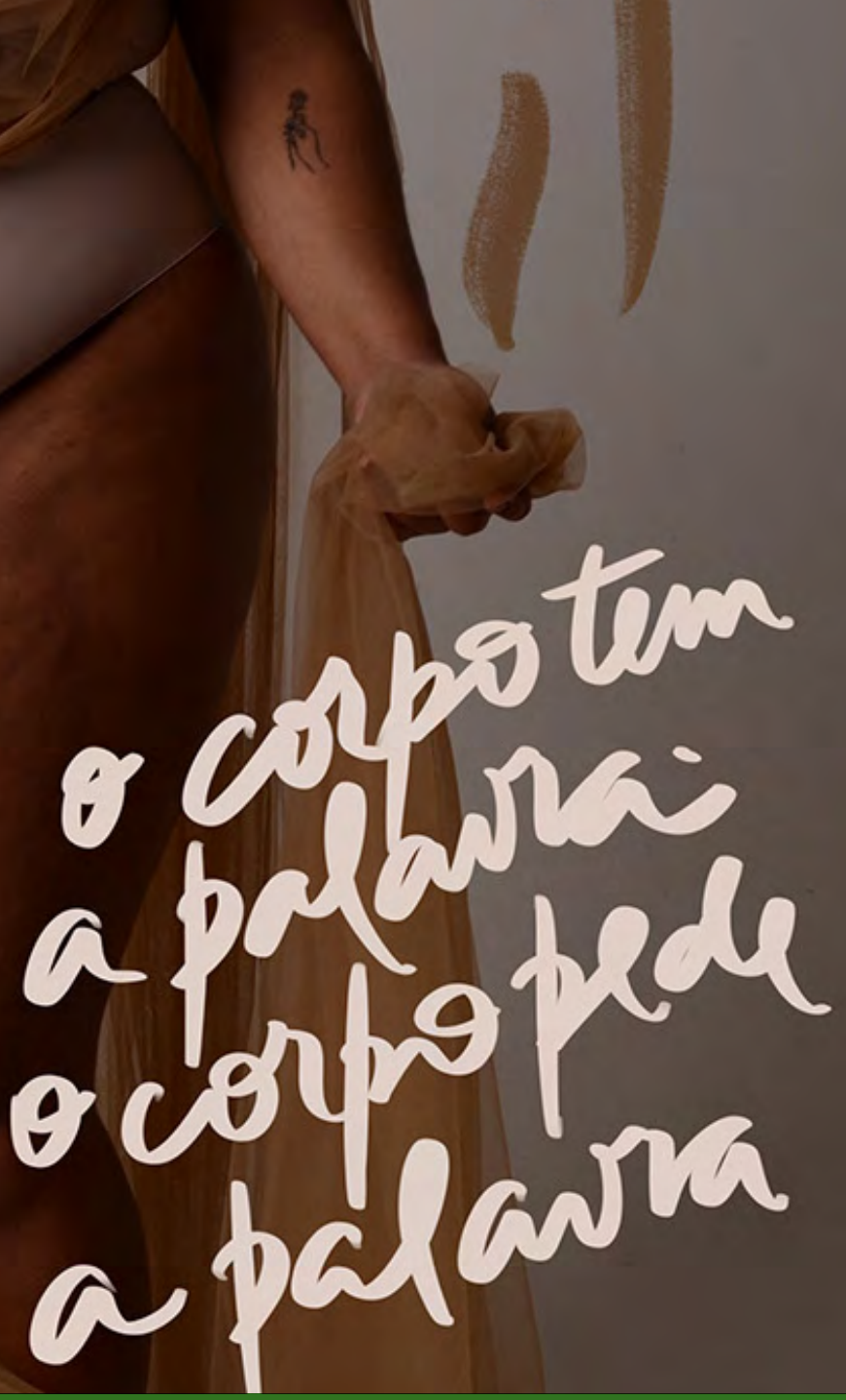

dObras | NÚMERO 33 | SETEMBRO-DEZEMBRO 2021 https://dobras.emnuvens.com.br/dobras | e-ISSN 2358-0003 


\section{Márcia Metz ${ }^{1}$}

ORCID $0000-0002-0565-835 X$

[resumo] 0 texto traz reflexões acerca da relação das atrizes gordas com os figurinos de suas personagens e com figurinistas. Contextualiza a importância do figurino na realização de um espetáculo, sendo muito mais do que uma roupa. Aborda um pouco da realidade das atrizes gordas. A partir de alguns depoimentos de atrizes e vivências pessoais da autora certas tensões são evidenciadas nessa relação atrizes gordas/figurinos/figurinistas. Quando falamos de figurinos pensados para atrizes que não são magras, um reflexo da opressão estética e da gordofobia que vigoram socialmente aparecem no meio teatral. 0 artigo com essas ponderações propõe que repensemos essa estrutura para que as atrizes gordas possam usar quaisquer tipos de figurinos, sem que isso se torne uma problemática.

\section{[palavras-chave] Atrizes gordas. Figurinos. Figurinista. Opressão estética.}

[abstract] The text reflects on the relationship between fat actresses and the costumes of their characters and with costume designers. It contextualizes the importance of the costume in the performance of a show, being much more than an outfit. It addresses a little of the reality of fat actresses. From some testimonies of actresses and personal experiences of the author, certain tensions are evidenced in this relationship between fat actresses/costumes/costume designers. When we talk about costumes designed for actresses who are not skinny, a reflection of the aesthetic oppression and fatphobia that prevail socially appears in the performing arts environment. The article, with these considerations, proposes that we rethink this structure so that fat stars can use any type of costume, without this becoming a problem.

[keywords] Fat actresses. Costumes. Costume designer. Aesthetic oppression.

Recebido em: 04-05-2021

Aprovado em: 02-06-2021

\footnotetext{
${ }^{1}$ Mestrado em Artes Cênicas pela Universidade Federal do Rio Grande do Sul. E-mail: marciametz@yahoo. com. Lattes: http://lattes.cnpq.br/2684263403224514.
} 


\section{Introdução}

Uma mulher gorda tem muito mais dificuldade para se vestir satisfatoriamente do que uma mulher não gorda. Encontrar fartas opções de roupas a partir do tamanho 44, em lojas de departamentos, pode ser uma caça ao tesouro. Conforme o manequim aumenta, diminuem as chances de encontrarmos vestes que nos caibam. É item raro para pessoas gordas uma roupa que sirva confortavelmente, que seja bonita e com um preço razoável. As mulheres gordas conhecem bem essa realidade, não há novidade para elas nessas afirmações, nem para os homens gordos.

A cultura que vigora enaltece um padrão de beleza magro, jovem e branco. Socialmente a magreza é desejada e a gordura vilanizada. Mesmo assim, com todas as opressões e barreiras que as pessoas gordas sofrem, elas seguem existindo, insurgem e florescem nos mais variados solos. Gordas desempenham papeis sociais e profissionais em diversos âmbitos, inclusive em espaços culturalmente relacionados a pessoas magras. Em trabalhos diretamente relacionados à corpa ${ }^{2}$ (professoras de ginástica, esteticistas, nutricionistas, etc.), a tal 'beleza padrão' acaba sendo fundamental, ou seja, ser magra (o) é um fator que pode determinar a escolha de determinada profissional (BERGER, 2006). Segundo Naomi Wolf (1992, p. 34):

Havia uma classe bem definida daquelas remuneradas explicitamente pela sua "beleza": trabalhadoras nas profissões de grande visibilidade como as modelos de moda, as atrizes, as bailarinas e as que se dedicavam ao sexo por remuneração mais alta, como as escorts. Quanto mais fortes ficaram as mulheres, maior o prestígio, a fama e o dinheiro dispensados a essas profissões. Elas são mantidas cada vez mais acima da cabeça das mulheres que desejam subir na vida, para que estas as imitem.

Quantas mulheres ficam fascinadas ao verem a beleza e a magreza das divas de cinema, novela ou seriado nas telas? Quantas mulheres não suspiram desejando ser iguais às celebridades? As mulheres que alcançam o estrelato cumprindo à risca o ideal da representação de um padrão de beleza pagam, literalmente e metaforicamente, para manterem sua aparência inalterada ao longo dos anos. Elas não podem engordar e nem deixar transparecer qualquer sinal de envelhecimento. Rugas e cabelos brancos não são bem vistos e existe uma larga oferta de produtos para "resolver" esses "problemas".

Pense em três atrizes que você admira muito. Pensou? Quantas são jovens? Quantas são brancas? Quantas delas são mulheres gordas? Há muito tempo o ideário de que uma atriz deveria ser bonita (magra) está consolidado em nosso imaginário. Porém, as atrizes

\footnotetext{
A utilização da palavra corpa ao invés de corpo, para se referir especificamente ao corpo das mulheres é um neologismo que vem sendo utilizado por estudiosas do assunto. Encontro na Artista Visual Fernanda Magalhães uma justificativa para este uso. 0 uso da palavra Corpa é uma busca em usar palavras no feminino, tentando desconstruir nossa linguagem que é toda construída no sistema patriarcal. Estou falando de um corpo de mulher, carregado de sentidos feministas e questões que rebatem as normas. Este corpo se intitula como a corpa e assume isso em seu uso diário.
} 
gordas já existiam séculos atrás, existem hoje e seguirão existindo. A cada dia que passa elas interpretam mais e mais personagens que não sejam estereotipadas como a gorda engraçada, a serviçal, a amiga da protagonista ou aquela romântica que faz de tudo para emagrecer.

Os estereótipos negativos atribuídos às atrizes gordas são escancarados no meio audiovisual e suavizados no meio teatral e é desse lugar que tenho maior propriedade para falar: o teatro. Sem nenhuma romantização posso afirmar que o espaço - tempo - lugar que constitui o teatro é mais receptivo à diversidade, inclusive de corpas e corpos que estão à margem dos padrões. Não devemos esquecer que mesmo que o teatro tenha um caráter mais independente e alternativo ele é um reflexo da sociedade na qual está inserido, com tudo o que há de bom e ruim na mesma. Por isso, mesmo sendo um lugar onde muitas atrizes gordas puderam ser e existir, ele vai privilegiar corpas magras em muitos momentos.

Atrizes e atores ao pisarem no palco trajam um figurino, a roupa da personagem que interpretam. A menos, evidentemente, onde a montagem exija que estejam nus por completo. Aqui trago algumas reflexões sobre a relação das atrizes gordas com o figurino.

Conceituo esse componente teatral, falo sobre as atrizes gordas e busco traçar paralelos nessa relação com alguns depoimentos pessoais. Se a relação das mulheres gordas com o mundo da moda possui uma série de características particulares, que vão desde a encontrar uma roupa qualquer para vestir, mesmo nas confecções plus size, até a poder expressar uma identidade pela vestimenta, talvez a relação do figurino teatral, que é também uma veste, possa ser diferente para essas mulheres. Afinal, em tese, os figurinos são confeccionados para a atriz ou o ator que irá trajá-los, não importando previamente qual o tamanho a indumentária deva ter.

\section{Figurino: a roupa teatral}

Muito mais do que uma simples roupa, um figurino carrega uma série de significados. 0 figurino teatral está a serviço de constituir a identidade de uma personagem, é o invólucro da corpa/corpo que assistiremos. Os nossos olhos percebem uma coisa só no instante que veem a artista no palco. A atriz, a personagem e o figurino formam um conjunto que se complementa, não são itens separados e nem se pretende que o sejam. Segundo Rosangela Cortinhas (2010, p. 7), o figurino "na cena contemporânea, tem levantado questões muito particulares nos efeitos infinitos que dispõe na representação de si mesmo e na projeção de signos ou imagens que ele projeta na cena", assim ele, o figurino, também está representando no palco.

Podemos identificar certas funções, profissões e até estilos de vida através da vestimenta de alguém. As roupas adquirem o status de signo, pois representam um objeto. Elas exprimem o eu subjetivo do sujeito (ACOM, 2013).

Para Aliana Aires (2019, p. 15), a experiência central de consumo em nosso cotidiano está calcada na moda, sendo que esta: 


\begin{abstract}
[...] amplia sua influência na formação da identidade dos indivíduos, que ganham autoestima e prazer ao escolher as peças que vão vestir e ao compor seu estilo. A circulação do estilo de vida fashion, com a estilização do "eu" proposta pela moda e intensamente veiculada e publicizada pela mídia, auxiliou na constituição de sujeitos que guiam seus comportamentos por meio da moda e de seus estilos. Esse processo é acompanhado também por uma mudança na formação da subjetividade. Antes seguíamos um modelo de identidade baseado em aspectos sociais fixos [...] no qual virtudes e valores [...] eram valorizados em detrimento da aparência externa. Hoje seguimos um modelo exterior da identidade, em que a aparência corporal passa a identificar fortemente o sujeito.
\end{abstract}

As vestes de nosso dia a dia assumem valores simbólicos bastante expressivos no que se refere a nossa personalidade. No palco não estamos buscando expressar um sujeito artista, mas sim uma personagem e as suas características. 0 figurino também esta a serviço de representar subjetividades, mas vai além, ele é um dos componentes essenciais para o espetáculo, seu valor de transformação é afirmado pelo ator que o veste e que impõe a ele seus traços, suas marcas, seus gestos, fazendo dele a pele pela qual o personagem respira (CORTINHAS, 2010). Além disso, o figurino faz o caminho contrário que percorre a roupa cotidiana, ao invés de lermos na indumentária a personalidade de um indivíduo, partimos das informações prévias da personagem. Detalhes escritos no texto teatral, em rubricas da dramaturgia ou das construções feitas a partir dos improvisos das atrizes e atores, assim “a vestimenta de um personagem deve transmitir e representar a sua essência já estabelecida por um autor (ACOM, 2013, p. 96)", seja ele dramaturgo, diretor ou intérprete.

0 teatro está mais interessado em ficcionalizar o real, colocando uma espécie de zoom sobre o que é encenado, do que tentar ser uma representação tal e qual da vida cotidiana. A vestimenta, as roupas e adereços de atrizes e atores seguem essa mesma toada operando na estrutura imaginária do personagem, há um pacto que convenciona o seu uso, não importando mais a sua concretude. 0 figurino pode ainda assumir diferentes formas: a saia rodada de uma mocinha pode, rapidamente, se transformar em um hábito religioso na cabeça da mesma, por exemplo (CORTINHAS, 2010).

Em um palco teatral tudo é signo ou símbolo. Costumamos dizer que se algo está lá por acaso - na cena - não deveria estar, cada elemento do cenário, cada movimento da atriz e cada detalhe de seu figurino são pensados com critérios bem estabelecidos para contar uma história. 0 figurino é um elemento que traz em si muita informação, tudo nele pode ser lido. Para Patrice Pavis (2003, p. 165) “o figurino é muitas vezes uma cenografia ambulante, um cenário trazido à escala humana e que se desloca com o ator", o autor ainda discorre que para ele no teatro o figurino desempenha uma função de estabelecer uma natural comunicação entre a pessoa física e privada do ator e a personagem que ele está criando, um "perfeito agente duplo, ele é levado por um corpo real para sugerir uma personagem fictícia”. Já para Jean-Jacques Roubine (1998, p.146) o figurino "deve ser considerado como uma variedade particular do objeto cênico", afinal ele contribui para a elaboração da personagem pela atriz de forma específica e constitui um conjunto de formas e cores que modificam o espaço do espetáculo, passando a integrar o mesmo. 
Independente da estética escolhida para a encenação, o figurino estabelece essa relação com o interior da cena e outra com o exterior, que se refere ao contexto social e histórico da peça teatral a qual pertence. Ele "carrega sobre a cena um jogo maior: o mundo espetacular de uma cultura" seja ela parcialmente ou totalmente inventada (CORTINHAS, 2010, p. 20).

Os seres humanos estão em constantes relações interiores e exteriores, tudo é atrito e fricção, as contradições, sonhos e frustrações que levam a embates com nós mesmos são dessa ordem interna, todo o resto é externo. A roupa que usamos é análoga a uma película que está muito próxima ao nosso mundo interno, mas, de fato, se relaciona com o que está fora de nós.

O corpo de uma atriz ou de um ator quando é vestido por um figurino transforma o sujeito em imagem, novamente destaco esse conjunto composto por três partes que os olhos percebem como uma só: atriz/personagem/figurino. É um estímulo de via dupla a relação de uma atriz com o seu figurino, ele pode inspirar na criação da personagem e ela pode animá-lo de outras formas para as quais talvez não tenha sido pensado.

A roupa historicamente funcionou como ferramenta de controle social e de manutenção de valores. A variante desta para a cena, o figurino, vai percorrer um caminho similar. 0 ideal de uma mulher no século XIX, por exemplo, era de que ela fosse "frágil" e de que sua função fosse voltada para a instituição familiar; feminina e delicada. As roupas, à primeira vista, reforçavam tal estereótipo. A construção da imagem de "progenitora" e de "indefesa" através das roupas, se dava pelo uso de diversas anáguas, saias e espartilhos muito apertados de forma a afunilar a cintura e aumentar o tamanho das saias (MACIEIRA; ANDRADE, 2010).

E as mulheres gordas? Para elas, mesmo com todos esses recursos, era mais difícil aparentar tal fragilidade. Os espartilhos eram usados desde cedo, uma tortura silenciosa que podia provocar desmaios e acabar por deformar o corpo. 0 uso da crinolina e da anquinha conferiam o volume e o formato arredondado aos quadris, simbolizando a fertilidade. A partir da década de 1920, a moda das mulheres aboliu a crinolina e as anquinhas, bem como os espartilhos convencionais. No entremeio das duas grandes guerras houve a necessidade do corte nos gastos com tecidos e na exuberância das roupas das mulheres e, por conta disto também, as saias se tornaram mais curtas e o corte das roupas mais flexível, de modo que elas pudessem sair para trabalhar e o resultado na aparência se tornasse mais ou menos homogêneo. Isso obviamente não era extensivo a todas as classes sociais, muito pelo contrário, em uma época de recessão qualquer brilho a mais em uma vestimenta elevaria a condição social daquela que a estivesse ornando (MACIEIRA; ANDRADE, 2010).

Encontramos, sem muita dificuldade, imagens de atrizes nesse período (anos 1920/1930) ostentando algum glamour. No pós-guerra, a valorização da saia enquanto definição de feminino ${ }^{3}$ (usado como sinônimo para tudo que se refere as mulheres) esteve em voga com a criação do New Look de Dior e, posteriormente, nos anos 1960 e 70, a moda seguiu tendência muito mais andrógena tanto para mulheres quanto para homens: o corte

\footnotetext{
Feminino está no dicionário como algo relativo às mulheres, mas evito usar esse como um sinônimo, pois existe um apelo que busca uma representação de feminilidade, uma construção baseada e ancorada na exacerbação a determinados atributos tais como a graciosidade, a harmonia das formas, a beleza, a sensualidade e a delicadeza.
} 
das roupas foi alargado nos anos 1970, comportando a ideia de esconder o corpo das mulheres, enquanto que os homens passaram a usar cabelos compridos (MACIEIRA; ANDRADE, 2010).

Ao longo do século XX, o figurino, assim como os demais elementos visuais do espetáculo, estabeleceu-se como um vetor ativo na construção do sentido da cena, incorporando novas funções, ou seja, não era apenas uma roupa bela e vistosa no palco. Os textos teatrais apresentam uma complexificação das personagens, do ponto de vista de um detalhamento de suas estruturas psicológicas, e uma ilustração meramente tipificada dos figurinos não atende mais aos questionamentos postos em cena. Nasceu assim a profissão do figurinista, que deveria estar atento às várias funções atribuídas ao figurino. É desejo recorrente das atrizes e atores, que a/o figurinista esteja presente ao longo do processo de criação teatral, não chegando apenas nas semanas finais para pensar nessa composição.

O figurino mantinha a sua função primeira de caracterizar a personagem, mas com muito mais camadas, revelando seus traços psicológicos, "estilo, preferências individuais ou meio social" (PAVIS, 2010, p.164). Trata-se de um elemento capaz de guiar o espectador em relação ao sexo, à profissão, a posição hierárquica, a classe social e a religião da personagem, sendo também um meio de indicar o tempo e o espaço da ação. 0 figurino contribui para o entendimento geral do espetáculo, permeando toda a dramaturgia. (MACIEIRA; ANDRADE, 2010).

$O$ teatro tem a potencialidade de alterar a nossa visão sobre aspectos da vida. Toda a arte, incluindo o teatro, pode desempenhar um papel ativo na mudança dos rumos de um país. Questionamentos levantados por ele podem causar um grande impacto, em um contexto em que a imaginação efetivamente toma o poder, no qual a transgressão e a criação caminham juntas, com o desejo de mudar um sistema, contestá-lo e fazer a diferença (XAVIER; MUNIZ, 2020).

Nesse sentido o figurino, além de tudo que já foi mencionado sobre ele, pode ser visto como um instrumento político, quase como um manifesto que transmite mensagens propositivas em uma melhora social.

\section{Figurinistas como mensageiras}

Os figurinos são criações artísticas de figurinistas, portanto, se os figurinos são elementos capazes de levar à cena diversas informações, são aqueles que os criam e os confeccionam os responsáveis por transmitirem certas ideias. De acordo com Wagner Ferraz e Anderson Souza (2013, p. 25):

O figurinista é responsável pela criação de figurinos. Projeta, pesquisa, cria, desenha, reaproveita e transforma figurinos já existentes, coordena a equipe de produção e organização de guarda-roupa de elenco artístico. Muitas vezes desenvolve todo o processo de criação e confecção do figurino ou coordena todo o processo, trabalhando com a contratação de serviços de outros profissionais. O figurinista precisa estar atento aos elementos que compõem a cena, como: cenário e objetos cênicos, iluminação cênica, noções de espaço, texto, coreografia, artistas, música, efeitos visuais e sonoros, maquiagem, entre outros. 
É uma tarefa criativa e de extrema responsabilidade. Mesmo que a/o figurinista esteja em sintonia com a concepção estética que lhe foi dada por determinado artista, ou grupo teatral, ou diretora, ou encenador, etc., e que busque ser fiel a essas escolhas sem impor o seu gosto, ela ou ele automaticamente estará imprimindo ao figurino seus valores e concepção de mundo. Em termos mais concretos podemos destacar certas competências pontuadas por Wagner Ferraz e Anderson Souza (2013), para quem deseja ser figurinista, tais como: desenhar a figura humana, fazer uma ficha técnica, estudar as cores, estudar sobre a tecnologia têxtil e os materiais mais adequados, ter noções de corte e costura e conhecer modelagem e ergonomia, entre outras.

A questão da modelagem e da ergonomia fala exatamente sobre a singularidade de cada corpa ou corpo, na sua postura, no conforto ou desconforto que a veste deve ter sobre o mesmo. Existem muitos tipos de corpas e corpos e seria impossível exigir do profissional figurinista que conhecesse todos eles. Porém a partir desta assertiva fica evidente que uma noção geral de diversos tipos de corpas e corpos é necessária. Incluindo a corpa gorda.

Em um mundo onde a moda, o vestuário e a beleza estão imbricados numa representação de padrão de beleza magro, indago: que tipo de representação de padrões e de beleza as/os figurinistas tendem a criar? Se a nossa cultura enaltece a magreza, é possível que figurinistas enalteçam formas corporais mais fartas?

Em 2016, cursei uma disciplina sobre indumentária no Curso de Teatro. Entre diversas aprendizagens e práticas estava a criação de figurinos. Em um primeiro exercício o professor definiu personagens de um determinado contexto social. Mais tarde poderíamos utilizar aquele espaço para criar os nossos próprios figurinos, visto que muitas alunas e alunos estavam as vésperas de montar o seu espetáculo de conclusão do curso.

Uma dica basal dada por nosso mestre foi o uso de 'corpinhos' que encontramos na internet, desenhos de silhuetas de homens e mulheres. Ao reproduzi-los em papel vegetal temos um modelo permanente para a criação dos figurinos. Ao procurar os 'corpinhos' fiquei incomodada por só achar modelos magérrimos (algo similar a um tamanho 36). Afinal eu iria ainda criar um figurino para mim mesma, e na época eu vestia um manequim 46. Insisti na pesquisa até achar um 'corpinho' um pouco maior, algo equivalente a um tamanho 44.

0 primeiro exercício da disciplina tinha a figura de uma espécie de heroína ou presidenta digna e bondosa. Meu trabalho trouxe a estética dos personagens dos filmes e HQs X-Men. Defini a personagem Tempestade como inspiração para a minha presidenta, mas busquei um traje mais formal para ela, este baseado em um blazer e saia vermelhos usado em uma ocasião por Simone de Beauvoir ${ }^{4}$. E por ser a minha protagonista ela era a de 'corpinho' maior. No dia da apresentação, espalhamos nossos desenhos sobre a bancada e a seu tempo cada um foi falado sobre as suas criações. Ao ver a minha heroína, de salto, capa, soltando raios e gordinha, uma colega, sem saber de quem era a ilustração, soltou uma gargalhada e disse: nossa parece uma dona de casa. Minha resposta foi imediata: por que ela é gorda?

\footnotetext{
${ }^{4}$ Simone de Beauvoir (1908-1986) foi uma escritora, intelectual, filósofa existencialista, ativista política, feminista e teórica social francesa.
} 
A referida colega deu um riso sem graça e alguma justificativa sem sentido. Inclusive entre os meus croquis havia uma inspiração na personagem Vampira dos X-Men, usando luvas de borracha e representando uma parte do povo na figura de uma trabalhadora doméstica. Por que foi mais fácil chamar de dona de casa uma gorda bem trajada do que uma magra nitidamente com adereços para realizar uma faxina?

Ser uma dona de casa ou uma trabalhadora da limpeza não são deméritos, muito antes pelo contrário, exalto aqui essas funções normalmente exercidas por mulheres sem descanso. Mas o comentário da estudante de teatro - magra - com riso irônico buscou atrelar aquela corpa a uma função social entendida como menos nobre. Afinal uma gorda para ela, estando bem vestida não poderia ser nada além do que uma dona de casa.

0 relato pessoal acima levanta duas questões. A primeira é que não há nem mesmo material, moldes e modelos facilmente disponíveis de corpas e corpos gordos. Os moldes sendo magros, figurinistas tendem a aprender a criar figurinos para corpos magros. A segunda diz respeito ao momento em que a figurinista (função que eu estava exercendo naquele momento) apresenta uma corpa fora do padrão e é recebida com estranheza e de forma jocosa.

Flavia Durante, criadora do evento Pop Plus uma das feiras de moda plus size mais importantes do Brasil, ministrou uma aula do Curso Insurgências Gordas II, que foi realizado no inicio de 2021, de forma remota. A empresária falou de sua experiência com o universo da moda, confirmando a primeira questão do parágrafo anterior, as escolas de moda não fornecem moldes para numerações maiores. Alunas gordas saem do curso de moda sem nunca terem experimentado criações de numerações maiores, ou seja, sem terem pensado uma roupa para a sua própria corpa. Alana Aires (2019, p. 18), afirmou que "valores externos evidenciam a subjetividade dos seres" e indagou: "Como se constrói uma identidade a partir de algo que lhe é negado?". Concordo com a autora e questiono: como figurinistas podem construir figurinos com subjetividades invisibilizadas, como a das corpas e corpos gordos?

Como bem definiram Mariana Xavier e Rosane Muniz (2020, p. 65) o "figurino é arte, moda é arte, e arte tem o papel de inspirar, questionar e até mesmo incomodar, proporcionando diferentes sentimentos - a quem faz e a quem vê", mas para inspirações diversas é preciso que figurinistas tenham referências mais amplas e múltiplas sobre corpas e corpos insurgentes.

Figurinistas são artistas que podem transmitir mensagens em seus figurinos, sendo responsáveis por mudanças pessoais ou sociais "o que prova a característica autoral e dramatúrgica do artista denominado como figurinista. E a importância da liberdade de expressão para a criação artística" (XAVIER; MUNIZ, 2020, p. 75). Para que estas mensageiras e mensageiros possam contar outras narrativas é importante que ampliem o seu imaginário com novas e variadas representações de padrões de beleza e da quebra de todos eles. 


\section{Atrizes gordas}

Para Judith Butler (2002), a sociedade busca dar funções específicas a cada tipo de corpa e corpo. De formas reinventadas, a literatura apresenta a corpa da mulher como uma potência para ser bela, mãe, feminina e como uma figura santificada, mítica que é disposta a sacrifícios. Delicadeza, boniteza e feminilidade são traços dificilmente atribuídos às mulheres gordas. Denise Sant'Anna (2001) destaca que as pessoas gordas são mal vistas e por isso precisam compensar o desconforto que geram com o seu peso, sujeitando-se a um trabalho duro ou sendo uma "boa gorda". Humoristas gordas seriam perfeitas, já que não satisfazem como mulheres as potencialidades da beleza e da feminilidade, que ao menos façam rir aqueles que tiverem de olhar para elas.

Com a citação anterior de Naomi Wolf (1992) evidenciamos que as atrizes faziam parte de uma das profissões onde se esperava que as mulheres fossem belas e magras. Quando procuramos especificamente sobre a história das atrizes gordas, esse histórico não aparece. É fato que a história, ou, a ausência dela, sobre as mulheres nas artes não é diferente daquela registrada a respeito delas de um modo geral. Todas as invisibilidades ocorridas não são inocentes, a ausência das mulheres como figuras que pensaram a arte não pode ser encarada como ocasional (ROMANO, 2009). A ausência de registros de uma mulher artista e gorda são ainda mais explicáveis pelo exposto até aqui.

E as atrizes gordas e negras? Infelizmente o apagamento nesse sentido é brutal. A história narrada sobre as mulheres no mundo já traz uma série de complicadores, visto que ela foi sendo contada e registrada pelos homens. Mas quando mencionamos isso precisamos lembrar de que mulher estamos falando. Marielle Franco ${ }^{5}$ (2017, p.91) pontuou essa diferença afirmando que "ainda que o machismo histórico e institucional seja uma das bases da formação social brasileira, as mulheres negras e faveladas reúnem vários outros aspectos de interdição, dominação e restrição de direitos frente às demais mulheres da cidade". E ainda temos a fala plena e absoluta de Sueli Carneiro sobre as mulheres negras:

Quando falamos que a mulher é um subproduto do homem, posto que foi feita da costela de Adão, de que mulher estamos falando? Fazemos parte de um contingente de mulheres originárias de uma cultura que não tem Adão. Originárias de uma cultura violada, folclorizada e marginalizada, tratada como coisa primitiva, coisa do diabo, esse também um alienígena para a nossa cultura. [...] é possível

\footnotetext{
Marielle Franco (1979 -2018): foi uma socióloga (PUC-Rio), mestra em Administração Pública (UFF). Trabalhou nas organizações Brasil Foundation e o Centro de Ações Solidárias da Maré (Ceasm). Foi eleita a vereadora da Câmara Municipal do Rio de Janeiro pelo PSOL, sendo em 2016 a quinta vereadora mais votada. Criticava a intervenção federal no Rio de Janeiro e da Polícia Militar, denunciava constantemente abusos de autoridade por parte de policiais contra moradores de comunidades carentes. Foi assassinada a tiros, juntamente ao seu motorista Anderson Pedro Mathias Gomes, no dia 14 de março de 2018, em situações até o momento não esclarecidas.
} 
afirmar que um feminismo negro, construído no contexto de sociedades multirraciais, pluriculturais e racistas - como são as sociedades latino-americanas -, tem como principal eixo articulador o racismo e seu impacto sobre as relações de gênero, uma vez que ele determina a própria hierarquia de gênero em nossas sociedades. (CARNEIRO apud RIBEIRO, 2017, p. 48-49).

Certamente o marcador identitário da cor da pele teve implicações diferentes às mulheres gordas negras, mas as referências históricas a que tive acesso e apresento aqui não fazem essa distinção, evidenciando que falam de corpas brancas.

A doutora em Ciências Sociais, Karen Marcelja (2016, p.10) alerta para uma construção social na qual apenas as pessoas consideradas bonitas têm o direito a uma vida amorosa e sexual bem-sucedida, tanto na ficção como em nosso cotidiano. Para ela "nosso imaginário não está habituado a ver os feios vivendo esse tipo de realização, o que nos leva a associar a sensualidade à beleza e a glorificar a 'tríplice aliança' formada por beleza, magreza e felicidade".

As artistas podem (e devem segundo a ótica patriarcal) ornar os espaços por onde circulam. Esse por sinal, é um outro conceito comumente relacionado à beleza: a arte. Há uma crença tácita no sentido de que a arte deve ser bonita, ainda que a beleza seja subjetiva. Não só as atrizes, mas, por exemplo, no mundo das divas pop, que eternizam figurinos em shows e turnês, vemos corpas magras, trabalhadas e recauchutadas em profusão. É a beleza esperada de uma artista mulher.

0 que coube às gordas que resolveram ser atrizes? Estereótipos de amas, criadas, mães, bruxas, sonhadoras e especialmente de engraçadas. 0 teatro manteve, até certo ponto, essas repetidas representações, mas rompe com isso, permitindo que as atrizes gordas possam ser o que quiserem em cena. No meio audiovisual esse padrão, a passos lentíssimos, vem sendo questionado, no Brasil em novelas televisivas, nomes como: Débora Lamm, Guilhermina Libanio e Mariana Xavier interpretaram personagens fora desses estereótipos, com narrativas bem-sucedidas e sem a sua corpa sendo uma questão.

Em filmes e séries estadunidenses nomes como Queen Latifah, Chrissy Metz e Nicola Couglhan, também tem um currículo de protagonismos não estereotipados. E no teatro brasileiro podemos citar Teuda Bara, Letícia Rodrigues e Grace Passô, como mulheres de corpas fartas que dão vida a diversas narrativas teatrais.

Questões de representatividade passaram a ter destaque na última década, Aliana Aires (2019, p.18) falando da moda para pessoas gordas salienta que "especialmente nos últimos dez anos, observamos a criação e intensificação do mercado de moda plus size em âmbito global, impulsionado por movimentos de valorização da diversidade que emergem na esfera contemporânea". No teatro é possível perceber isso pela intensificação de trabalhos que são criados a partir das inquietações dos artistas e não partindo de um texto dramatúrgico prévio. Gisela Habeyche, atriz e gorda, afirmou que "nesse momento sim existem muitas oportunidades de se contar a própria história pessoal [...] aparecem muitas oportunidades e expressões teatrais de contar as histórias diferentes [...] para trazer discussões sobre o que o mundo apresenta (HABEYCHE apud METZ, 2019, p. 100)" e nesse sentido todos os corpos fora da representação dos padrões estariam privilegiados na cena. 
Para Rosangela Cortinhas (2010, p. 19) “o figurino materializa o personagem e privilegia a sua silhueta em todas as suas proporções". Ouso dizer que no caso das atrizes gordas ele "deveria" privilegiar, mas nem sempre é o que acontece. A figurinista segue dizendo que "o corpo do ator é transformado em imagem, lugar originário do sensível. Toda a imagem produz efeitos, para quem as recebe e também para quem a produz".

Toda corpa em cena, seja magra ou gorda, ou mid size 6 irá criar uma imagem com o conjunto personagem + figurino. Toda corpa, com qualquer que seja o figurino.

Após esboçar um pouco sobre o histórico e a falta dele sobre as atrizes gordas, identificando as personagens que comumente foram atribuídas a elas e também que esta realidade está se modificando, trago alguns relatos mais atuais da relação delas com os figurinos.

\section{Atrizes gordas vestindo figurinos}

Entre os anos de 2018 e 2019 entrevistei e conversei com algumas atrizes, gordas e magras, a respeito das atrizes gordas de teatro. Depoimentos coletados de forma individual e coletiva que serviram de instrumento na minha pesquisa. A partir destas falas o figurino ou a/o figurinista surgiu como uma questão. Abaixo segue um trecho do depoimento da 'atriz $A^{\prime 7}$ :

Talvez o meu olhar seja generoso, mas a gente tem mais liberdade no palco do que outras mídias nos dão. Onde eu vejo às vezes (o corpo ser uma questão no teatro) é a relação com os figurinistas. Quando a gente fez o espetáculo X, a gente foi vestido de "bolinha de natal" (risos), todo mundo tinha uma roupinha dourada que parecia uma bolinha de natal, daí o figurinista fazia uns comentários do tipo "neste corpo fica bem, neste corpo não fica bem" [o figurino mencionado era colado ao corpo].

Na sequência um trecho da fala da 'atriz B':

Eu percebo que se eu engordo muito eu perco, além dos figurinos, um pouco de elasticidade, não é bem elasticidade, porque sou muito flexível, mas é diferente, limita um pouco, claro também tem o fator da idade também aí. [...] tem essa coisa de fazer espetáculo por muito tempo e ser gorda, tem vezes que o teu figurino não entra. Isso aconteceu agora, fazendo o espetáculo $\mathrm{Y}$, ao mesmo tempo que eu tenho vergonha é muito engraçado. A gente faz o espetáculo, para um tempo e retoma. A última vez que eu fui experimentar o figurino eu tava apertada, entalada, e é uma personagem que tem que ter um certo glamour, não dá atolada no figurino, não dá e não era um, eram seis figurinos. Um trabalho artesanal que

\footnotetext{
${ }^{6}$ Mid size, de modo simplificado, é um termo (como Plus Size) para falar de numeração das roupas, e se refere ao corpo que está no "tamanho médio" ou "no meio termo", ou seja, aquele corpo que não vai ser considerado plus size e nem magro.

${ }^{7}$ Neste artigo utilizarei de letras para me referir ao nome das entrevistadas, bem como de espetáculos que tenham mencionado.
} 
não há como aumentar. Então eu saí correndo pra tirar peso de cima. Em alguns momentos também o teatro me salva de ser mais gorda. Existe uma relação interessante nesse sentido porque os figurinos são o limite. Olha só se eu engordo mais do que o meu figurino como eu faço?

Agora eu trarei alguns relatos vivenciados por mim mesma. Às vésperas de concluir a escrita da minha dissertação uma colega me indicou para um trabalho como atriz, era a animação de uma festa infantil, onde eu seria uma fada dourada na história do Peter Pan, o cachê era ótimo e eu fiquei animada até a contratante perguntar, por telefone, as minhas medidas. Desliguei, peguei a fita métrica e retornei com os números anotados, ela disse que era impossível eu caber no figurino. Foi uma sensação levemente humilhante. Imagine, por um segundo, uma profissional de outra área qualquer (nada relacionado ao teatro) precisando de dinheiro, querendo trabalhar e ser impedida porque não cabe em um uniforme. Eu sei que esse exemplo é pontual, o figurino provavelmente foi confeccionado para a primeira atriz que fez a personagem, mas reforça que é esperado que uma atriz seja magra.

Realizamos um experimento Drag em uma das disciplinas do curso de Teatro, aprendemos sobre a história das Drag Queens e realizamos uma cena onde alunos e alunas procuraram se vestir e se maquiar usando Drag Queens conhecidas como referência. A faculdade possui um Guarda-Roupa, exatamente para que possamos utilizar de figurinos e adereços em nossas montagens. Algumas colegas acharam vestidos retrô lindíssimos, peças longas, babados, rendas e cores, nenhum desses figurinos me serviu, acabei improvisando com um vestido que trouxe de casa.

Em 2016 estava atuando em um espetáculo onde toda a concepção buscava algo onírico, poético e com certa sensualidade. Éramos quatro atrizes em cena e eu a única não magra do grupo. Nossa diretora chamou uma amiga graduada em moda para criar os nossos figurinos. Seriam saias e vestidos que semelhantes a camisolas e lingeries. A figurinista levou suas ideias e alguns tecidos e me "enrolou" em algo que se assemelhava a um saco de um tecido furta-cor esvoaçante. Percebi que eu estava feia comparada as minhas colegas, mas tive certo constrangimento em dizer isso, não ia causar um incomodo, a moça era a especialista ali. Felizmente uma das orientadoras do trabalho estava lá e se manifestou.

A referida orientadora é uma excelente professora e atriz, não só isso, ela é uma atriz gorda. Ela pediu licença e disse que aquilo não estava me valorizando, que havia quatro mulheres bonitas em cena e muito diferentes entre si, e esse contraste trazia beleza à encenação, mas que era preciso valorizar a corpa de cada uma com o figurino. Ela percebeu que eu não havia ficado à vontade. Levantou-se e apontou no meu corpo o quanto aquele pano estava "jogado" de um modo a me esconder. A figurinista, uma mulher magra, ficou bem desgostosa com a intromissão, mas cedeu, deu de ombros para que fizéssemos o que achássemos melhor. Fui salva pela empatia de outra mulher que entende o que é ter uma corpa farta.

Quando defendi a minha dissertação, uma das professoras da banca, a qual tenho respeito e carinho, mencionou um ator gordo do seu grupo, que estava engordando cada vez mais, que ela já tinha mandado ajustar o figurino dele algumas vezes e que se precisasse fazer novamente cobraria os custos do mesmo. Ela insistiu que é um problema quando uma atriz engorda, porque reformar um figurino custa dinheiro e o teatro já luta arduamente com a escassez de recursos financeiros. 
Todos esses relatos demonstram que a relação das atrizes gordas com seus pretensos figurinos e com figurinistas ocorre com certa tensão.

Com relação ao aspecto financeiro direi o óbvio: todo figurino tem um custo de produção, é verdade também que o meio teatral carece de recursos financeiros, mas há outras ponderações a serem feitas.

Reformar um figurino custará a mesma mão de obra da(o) costureira(o) seja para aumentá-lo ou para diminuí-lo. Nunca ouvi dizer que era problemático que a atriz emagrecesse por ter que ajustar o seu figurino. Dificilmente alguém tem o mesmo corpo ou corpa por toda vida, todos estamos sujeitos a engordes e emagrecimentos, voluntários ou não. Também temos outras alterações corporais: uma gravidez, uma lesão, um inchaço, etc. Questiono de o porquê das atrizes terem que buscar se ajustarem ao figurino e não o contrário. Muitos figurinos já poderiam ser pensados prevendo certas adaptações.

Outra coisa recorrente no teatro é a mudança da atriz que interpreta certa personagem. Para o bem do espetáculo é preferível escolher a atriz que melhor caiba no figurino ou aquela que melhor interprete o papel? Eu sei que nem sempre é possível pensar num figurino que seja totalmente ajustável e dependendo do material em que for confeccionado isso possa ser ainda mais difícil, como contou a "atriz B" que tem um figurino com "um trabalho artesanal que não há como aumentar". Todavia me parece mais uma desculpa pronta para todos os casos "não é possível aumentar o figurino porque gera custos", e que disfarça a preferência por atrizes magras que jamais engordem.

\section{Considerações Finais}

O elemento figurino teatral está inserido no ambiente do teatro, que por sua vez está em um recorte histórico e temporal de uma sociedade. Esta última na qual vivemos hoje é calcada em diversas opressões estéticas e tem como um dos preconceitos mais tolerados a gordofobia. As pessoas gordas, as mulheres em especial, são tratadas como seres abjetos que não devem ter o direito às narrativas de sucesso e felicidade, dentro e fora da ficção, bem como se vestirem do mesmo modo que as pessoas magras, a indústria da moda perpetuou essa ideia por muitos anos.

Então quando temos uma atriz gorda pronta para atuar no palco, entregando o melhor do seu talento, ela vai enfrentar todos esses fatores sociais nesse contexto: os figurinos pensados para pessoas magras; figurinistas que aprendem a desenhar para pessoas magras, com moldes e ferramentas; e materiais idealizados para corpos magros. A indústria da confecção que costuma ser mais cara para pequenos produtores (marcas locais, costureiras autônomas, etc.) do que para grandes marcas é a mesma que fornece tecidos para figurinistas, mais tecido pode significar mais custo e menos lucro. Porém, mais tecido e maior gasto financeiro, ao confeccionar um figurino para uma gorda, pode propiciar a chance de se fazer um trabalho ainda mais elaborado, original e vistoso.

É uma questão muito solitária para as atrizes gordas o embate entre figurinistas gordofóbicos (a gordofobia é estrutural e permeia todos os indivíduos de alguma maneira) e figurinos que não se encaixam. Muitas vezes a atriz gorda é a única no grupo a viver esse 
conflito, as demais estão tranquilas quanto ao que usarão e com a sua relação com a ou o figurinista. A atriz gorda pode não querer trazer este desconforto para o trabalho, acreditando ser apenas uma questão particular sua. Inclusive aceitando figurinos horrendos, pensados apenas em cobrir ao máximo as suas formas a todo pano, metaforicamente e literalmente.

O caminho para que esse cenário mude definitivamente é o mesmo das outras esferas sociais: reclamar, questionar e mostrar que existe uma diversidade corporal. Precisamos ainda evidenciar o óbvio de que as atrizes gordas existem e elas também usam figurinos. Ampliar a visão de figurinistas a respeito das atrizes gordas pode significar uma amplitude de narrativas contadas no teatro e, assim, contribuir para novas formas de entendermos o mundo. Isso passa também por ferramentas que possibilitem uma criação pensada para as gordas.

As atrizes gordas merecem, como todas as atrizes, ter a chance de contarem as mais diferentes histórias e transmitirem uma pluralidade de mensagens. 0 conjunto atriz/personagem/figurino estereotipado da gorda que apenas veste o figurino que couber e cubra a sua corpa, limitará as potências criativas dessas artistas.

Atrizes gordas são potências cênica e de vida, têm muito para ofertar. Que possam ser pensados figurinos para elas de acordo com toda essa exuberância e que juntos, atrizes gordas e seus figurinos, transmitam os melhores e mais belos signos, símbolos e mensagens nos palcos. Evoé. 


\section{Referências}

ACOM, Ana C. Figurinos em Hitchcock: moda e loiras gélidas. In: FERRAZ, Wagner; SOUZA, Anderson Luiz de. 0 trabalho do figurinista: projeto, pesquisa e criação. Porto Alegre: INDEPIn, 2013. p. 95-102.

AIRES, Aliana B. De gorda à plus size: a moda do tamanho grande. Barueri, SP: Estação das Letras e Cores, 2019.

BERGER, Mirela. Corpo e identidade feminina. Tese (Doutorado) - Programa de Pósgraduação em Antropologia, Departamento de Antropologia, Faculdade de Filosofia, Letras e Ciências Humanas, Universidade de São Paulo, São Paulo, 2006. Disponível em: https:// www.teses.usp.br/teses/disponiveis/8/8134/tde-22112007-150343/pt-br.php. Acesso em: 7 abr. 2021.

BUTLER, Judith. Cuerpos que importan: sobre los límites materiales y discursivos del "sexo". Tradução de Alcíria Bixo. Buenos Aires: Paidós, 2002.

CORTINHAS, Rosângela. Figurino: um objeto sensível na confecção do personagem. Dissertação (Mestrado) - Programa de Pós-graduação em Artes Cênicas, Instituto de Artes, Universidade Federal do Rio Grande do Sul, Porto Alegre, 2010. Disponível em: https:// lume.ufrgs.br/handle/10183/27280. Acesso em: 7 abr. 2021.

FERRAZ, Wagner; SOUZA, Anderson L. de. 0 trabalho do figurinista: projeto, pesquisa e criação. Porto Alegre: INDEPIn, 2013.

FRANCO, Marielle. A emergência da vida para superar o anestesiamento social frente à retirada de direitos: o momento pós-golpe pelo olhar de uma feminista, negra e favelada. In: BUENO, Winnie (Org.). Têm saída? Ensaios críticos sobre o Brasil. Porto Alegre: Zouk, 2017. p. 89-95.

MACIEIRA, Clarice; ANDRADE, Eduardo. O Figurino como objeto sensível na criação do espetáculo "Sob os Olhos dos Outros". Caderno de encenação, vol. 3, n. 11, 2010, n.p. Disponível em: https://www.eba.ufmg.br/cadernodeencenacao/index.php/revista/ article/view/7. Acesso em: 7 abr. 2021

MARCELJA, Karen G. Gordura e feminilidade: apontamentos sobre beleza e inclusão na cultura contemporânea. In: CONGRESSO BRASILEIRO DE SOCIOLOGIA, 18, Brasília, 2017. Anais [...] 
METZ, Márcia. Gordas, gordinhas, gorduchas: a potência cênica dos corpos insurgentes. Dissertação (Mestrado) - Programa de Pós-graduação em Artes Cênicas, Instituto de Artes, Universidade Federal do Rio Grande do Sul, Porto Alegre, 2019. Disponível em: https:// lume.ufrgs.br/handle/10183/202038\#. Acesso em: 5 abr. 2021.

PAVIS, Patrice. A análise dos espetáculos: teatro, mímica, dança-teatro, cinema. Tradução Nanci Fernandes. São Paulo: Perspectiva, 2003.

RIBEIRO, Djamila. 0 que é lugar de fala. Belo Horizonte: Letramento, 2017.

ROMANO, Lúcia R. V. De quem é esse corpo? A performatividade do feminino no teatro contemporâneo.Tese(Doutorado)-EscoladeComunicaçõeseArte,UniversidadedeSãoPaulo, São Paulo, 2009. Disponível em: https://www.teses.usp.br/teses/disponiveis/27/27156/ tde-25102010-162044/publico/1056874.pdf. Acesso em: 12 abr. 2021.

ROUBINE, Jean-Jacques. A linguagem da encenação teatral, 1880- 1980. Tradução Yan Michalski. Rio de Janeiro: Zahar, 1998.

SANT'ANNA, Denise B. Corpos de passagem: ensaios sobre a subjetividade contemporânea. São Paulo: Estação Liberdade, 2001.

WOLF, Naomi. 0 mito da beleza. Tradução Waldéa Barcellos. Rio de Janeiro: Rocco, 1992.

XAVIER, Mariana C.; MUNIZ, Rosane. O figurino como instrumento político: a importância da arte questionadora. Cena, n. 30, p. 65-76, maio/ago. 2020. Disponível em: https://seer. ufrgs.br/cena/article/view/104123/57751. Acesso em: 8 abr. 2021.

\section{Agradecimentos}

Revisora do texto: Caroline Silveira Sarmento, Mestra em Antropologia Social pela UFRGS, Bacharela em Ciências Sociais e Biblioteconomia, também pela UFRGS. E-mail: caroline. sarmento@gmail.com 